\title{
Minnesota Decides: a community blueprint for tobacco reduction
}

\author{
Daniel S Johnson
}

The national tobacco landscape is rapidly changing as a result of federal policy reform; action is taking place at the state level as well. During the past year, I have had the privilege of directing a state project called "Minnesota Decides: A community blueprint for tobacco reduction". This project has led to the creation of a statewide action plan for addressing tobacco use. This plan is influencing the debate over how to steward state tobacco settlement dollars. To date, outcomes include goals and action steps that are being embraced in various settings across the state as set forth in the plan by a cross section of Minnesotans. What makes this project different is the unique blend of public and private cooperation and input that led to its creation.

Tobacco use in Minnesota remains at epidemic proportions, according to the Minnesota Department of Health. One in every six deaths is tobacco related. Nineteen Minnesotans die every day as a result of tobacco use. Annual direct and indirect costs are estimated at more than $\$ 1.3$ billion. For a state that prides itself on the health of its citizens, it is very disheartening to know that $42 \%$ of students in grade 12 (age $17-18$ years) smoke on a regular basis. Tobacco use clearly is a major concern among Minnesotans - a concern no longer limited to public health. Health plans (such as Blue Cross and Blue Shield of Minnesota), health care providers, educators, law enforcement agencies, local government agencies, communities of faith, the non-profit sector, and businesses in Minnesota are increasingly invested in the problem.

Minnesota Decides is a public/private response to this broad base of concern about the tobacco epidemic. It is also a response to an opportunity. Because of tobacco's changing political landscape in this country, we now have an opportunity to change the culture of tobacco, starting with our own state. In Minnesota, even before our successful lawsuit, there was evidence that the tobacco industry was beginning to lose its influence. Two years ago, after years of work by the tobacco control community, significant youth tobacco access legislation was passed. We began to hear from new voices, and organisations began to express their outrage over the grip tobacco has on our culture. For example, health plans in Minnesota lobbied hard for passage of the youth access bill. Many other organisations that had not been a part of the tobacco debate began to weigh in. We're also experiencing a surge of support thanks to the tobacco lawsuit that was announced in August of 1994 by co-plaintiffs Minnesota Blue Cross and the State of Minnesota. (The suit was subsequently settled on May 8, 1998-a striking victory over "Big Tobacco".)

Minnesota Decides had a threefold purpose: (1) to create a public/private partnership; (2) to increase the number of stakeholders involved in the issue; and (3) to develop a state plan of action for tobacco reduction.

\section{A public/private partnership}

Blue Cross saw its role as convening this effort, but we recognised from the outset that we could not own the project. Our objective was to create a public/private partnership that would contribute the necessary resources, skills, and clout. As we built this project, we saw the value of having shared decision making, responsibility, and accountability. Ultimately, the project partners included Blue Cross, the Minnesota division of the American Cancer Society, the Minnesota Smoke Free Coalition, the Association of Minnesota Counties, and the state of Minnesota, represented by the Departments of Health and Human Services and the attorney general's office. When offered the invitation, each group enthusiastically jumped on board. Funding for the project was provided by a grant of $\$ 138000$ from the Blue Cross and Blue Shield of Minnesota Foundation.

\section{Broader stakeholder involvement}

The project was very grass roots in nature, beginning with local community involvement. During the summer of 1997, 10 community meetings were held around the state of Minnesota, in both metropolitan and rural areas. Our goal was to have meaningful dialogue during those town meetings, so we limited participation to $40-60$ people. We wanted to hear from people who had not previously participated in a public dialogue about tobacco control. We worked hard to see that the right people were in attendance. We wanted to attract smokers and non-smokers. We wanted to have different sectors of the community represented. Health care and public health officials were invited, but we also wanted to hear from members of law enforcement, local government, education, communities of faith, communities of colour, and youth and parents.

The business community was the other constituency that was important to involve. Business' stake in tobacco's economic equation
Daniel_S_Johnson

D S Johnson 
is high. According to Minnesota Department of Health research, more than $\$ 766$ million was spent in 1995 on lost work productivity resulting from tobacco use. Despite this fact, except for opinions expressed by tobacco retailers, the voice of Minnesota business was seldom heard on tobacco issues. To bring members of the business community to the table, we worked with individuals from local chambers of commerce, who served as meeting hosts and helped to secure business participation.

A significant challenge during town meetings was to limit the number of local public health staff and tobacco control volunteers in attendance. Their opinions are extremely important, but in order to ensure the proper dialogue, we needed to broaden the base of involvement yet limit the number of participants.

The town meetings were two hours long and were usually held during lunch. They featured both presentations and discussion. Presentations included the "state of the state" of tobacco use in Minnesota, featuring tobacco use trends and a recap of state tobacco control activity. Then a panel-typically including a county public health staff person, a health care provider, and a law enforcement officialdiscussed tobacco use and control at the local level. Participants then engaged in what was often a lively, and occasionally heated, discussion about what should be done to address the problem of tobacco use. Suggestions were numerous and ranged from simple to complex. Through these discussions over the course of the summer, we systematically collected information about what people thought about tobacco reduction around the state. After each town meeting, a report was written that provided a synopsis of what was said. Participants received the report, as did the local media.

By the end of the summer, more than 400 Minnesotans had had the opportunity to express their opinions and suggest solutions. Our goal-to increase the number of stakeholders involved in the issue-had been accomplished; $60 \%$ of participants had not previously engaged in a public discussion about tobacco.

\section{Plan of action}

Although ideas discussed at the town meetings were varied and diverse - ranging from banning tobacco products altogether to strengthening enforcement of existing laws and establishing worksite smoking policies - the consensus was that a broad based approach was needed. Minnesotans, by and large, recognised the need to change community tobacco norms.

The next phase of the project was a statewide summit, which took place in November 1997. During the period between the town meetings and the summit, we collected tobacco reduction best practices, both in Minnesota and across the country. We looked at the experiences of California and Massachusetts. We also went to 50 different Minnesota organisations and asked them to define an appropriate statewide goal for tobacco reduction. All of that information, coupled with the findings from the 10 town meetings, was brought forward during the two day state summit. More than 100 state leaders attended. Participants included senior officials from state government, law enforcement officials, business personnel, educators, members of communities of faith, individuals from communities of colour, and individuals from the health care community. We brought these people together to participate in a working conference with the objective of developing a blueprint for tobacco reduction.

Interactive audience polling technology was used to give everyone an equal voice. Issues or potential solutions were raised and participants anonymously expressed their opinions. By the end of the first day, participants had agreed on a three part goal for the blueprint: (1) to prevent a new generation becoming addicted; (2) to help smokers who want to quit; and (3) to protect Minnesotans from the impact of secondhand smoke.

On the second day, small groups worked toward finding common solutions. These groups were organised according to the following six settings for tobacco reduction, as described by the National Cancer Institute: worksites, points of access, schools, public places, health care settings, and the home.

By the end of the summit, recommendations were established for each setting. For example, for the health care setting, the recommendation is that providers need to be trained to assess, diagnose, and treat tobacco addiction, and payers need to reimburse for proven smoking cessation treatment. The summit also addressed how the various recommendations could be financed, most notably through an increased tobacco excise tax and from pending state tobacco settlement funds.

\section{Progress to date}

Following the summit, a 72 page blueprint for Minnesota tobacco reduction was produced. The document incorporates the findings of the town meetings, the recommendations from the summit, and the best practices and suggested goals submitted by Minnesota organisations. After a statewide media launch in April 1998, the plan was widely distributed. Thousands of copies of the plan and its executive summary have been disseminated to Minnesotans as well as to organisations nationally. One important audience was Minnesota policy makers; the blueprint is helping to shape the current debate over how the Minnesota legislature should appropriate state tobacco settlement proceeds. Other states have also referred to the blueprint as they pursue their own plans of action following the national tobacco settlement.

Beyond the actual plan, several outcomes have been achieved. First of all, Minnesota now has a lot more people invested as stakeholders in this issue-people who are informed and concerned, and who are interested and willing to be involved in this issue. Several communities used the Minnesota Decides town meeting as a springboard for their own local activities. For example, after the meeting in Winona, a southeastern Minnesota community 
of 27000 , the community got behind a grassroots initiative around tobacco. Over the course of several months, community members developed a program called TNT-Trash Nicotine Today. Winona schools, health care providers, parent organisations, the police department, the local college, and others are involved. The program sets an aggressive tobacco reduction goal and includes measures to monitor success. (For more information, go to www.winonahealthchallenge. org)

Where do we go from here? We are currently building on the success of this project by converting the state plan into areas of sustainable action. Blue Cross is supporting a series of grassroots community mobilisation efforts across Minnesota. We are also helping to develop an assessment instrument that will be used later this year to aid Minnesota communities to determine their readiness to change local norms about tobacco.

Minnesota Decides offers a strong message: Minnesotans want tobacco's grip on our culture to change. With the right resources, we can succeed.

For more information on Minnesota Decides, visit our web site at: www.mnbluecrosstobacco. com

\section{Questions and answers}

Q: What is the best way to approach a managed care organisation in order to generate interest and get them involved? Who are the best people to involve?

A: Managed care organisations are beginning to take seriously their role to reduce tobacco use. The stakes are simply too great to ignore. The Minnesota Decides blueprint defines appropriate roles for health care organisations to play, including managed care organisations. The obvious first course of action for managed care is to consider what it can do to help its smoking customers to quit, starting with offering a cessation benefit. Health plans are also demonstrating leadership in worksite cessation, community prevention, youth education, counter-advertising, public policy, and grassroots organising. The advent of state tobacco settlement resources to managed care will be a motivating factor, but not the only justification for embracing tobacco reduction strategies.

Start at the top, with the chief executive officer or chief medical officer. Reducing the tobacco epidemic means reducing costs and saving lives - two priorities high on the list of every managed care executive.

\title{
Strategic partnerships for addressing tobacco use
}

\author{
Wendy Bjornson
}

Tobacco-Free Coalition of Oregon, 1425 NE Irving, \#100, Portland, OR 97232 , USA;

bjornson@teleport.com W Bjornson

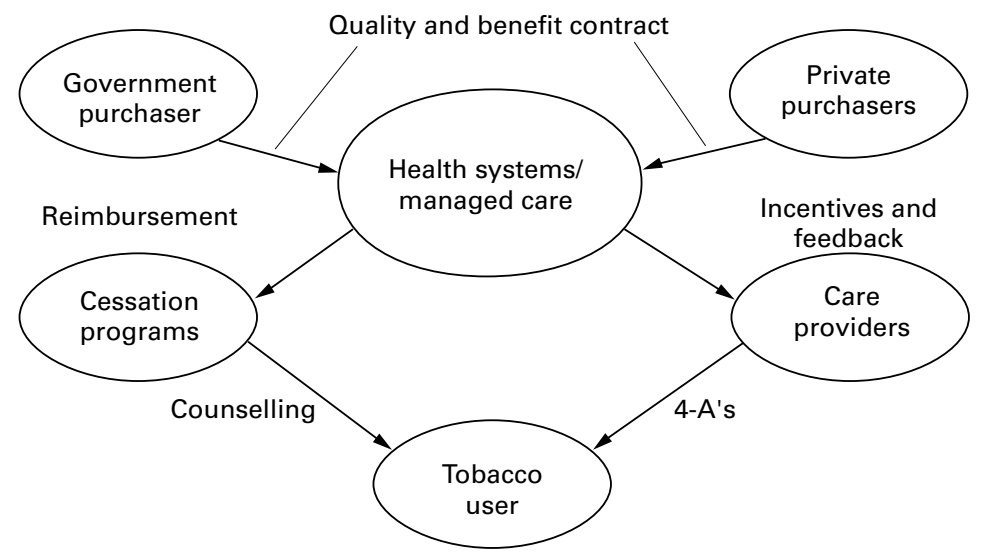

Figure 1 Oregon tobacco cessation project vision. into health care and other community settings. As we learn to work together in more effective ways, partnerships among multiple agencies and in communities become increasingly critical. In fact, it is through partnerships that we will ultimately achieve our goals.

The issue of partnerships in tobacco control is particularly important as we work to incorporate tobacco cessation and intervention 
goals of the project were consistent with the direction of managed care-that is, to help reduce health care costs in part by helping to prevent disease - the avenues for collaborating with managed care organisations were unclear. Further, even managed care organisations that had been working for some time to integrate tobacco cessation into primary care, such as Kaiser Permanente Northwest, had encountered many obstacles.

\section{Developing strategies}

The general discussion of strategies eventually turned to a discussion of "levers", those key strategies in managed care that could influence the adoption of cessation in routine health care. We knew that involvement and support at the highest levels of the organisation were necessary for any system wide change to be adopted. However, we found that organisational policy changes are usually not made unilaterally, but rather through a combination of key individual and key committee influences. We learned that cost effectiveness was an issue, especially since health plans investing in prevention may not realise the benefits of these investments as members shift to other plans, but only limited cost effectiveness data were available. We knew that a high level champion was indispensable to advocate for change within a plan, but we were unsure about how to locate these champions and persuade them to advocate for cessation.

At the same time we held our discussions, the 20 managed care organisations based in Oregon became increasingly interested in population based strategies for preventing disease. In addition to fulfilling their mission to provide good care to their members, we learned that plan based prevention strategies were needed to obtain accreditation from the National Committee for Quality Assurance and to retain non-profit status. Within health care plans, these strategies take several forms. Quality improvement mechanisms are used by plans to provide direction, services, training, monitoring, and feedback for health care providers. Financial incentives for physicians to provide quality preventive care are increasingly used by progressive plans. This led us to conclude that the managed care organisation itself and purchasers of managed care held the important levers for promoting cessation, influencing the delivery of services throughout the health care systems, and ultimately reaching the tobacco user (fig 1). A few of the 20 plans had begun to target tobacco cessation using these strategies. The experience of these early adopters, who became partners on the health systems task force, provided a practical basis for our project.

In addition to the practical experiences of these innovative health plans, a new staff person from the Oregon Health Division (OHD), with expertise in the link between public health and managed care, joined our task force. With this addition, the task force gained an important resource and ally in bridging the separate worlds of public health and managed health care.
The task force finally arrived at several strategies and began looking at partnership opportunities for implementation. The strategies were:

(1) Develop cessation guidelines for both medical care providers and for managed care plans, clarifying their respective roles and responsibilities. These Oregon specific guidelines would be based on the then newly released national Agency for Health Care Policy and Research (AHCPR) clinical practice guideline, ${ }^{1}$ but would be modified to fit Oregon's managed health care plan.

(2) Provide technical assistance to health plans for guideline implementation. We found that a significant barrier to implementation is the time and effort it takes to develop tools and strategies to make system changes. By providing training and on site technical assistance, some of these barriers can be reduced.

(3) Encourage large purchasers of managed care services (government and commercial) to use the Oregon guidelines when negotiating with health plans for services.

\section{Developing partnerships}

The partnership opportunity came when the largest purchaser of managed care in Oregon, the state Medicaid agency, began to target tobacco cessation as a key component of its preventive services. The Office of Medical Assistance Programs (OMAP) is the primary agency to implement the Oregon Health Plan (OHP), Oregon's health care reform effort. At present there are 14 managed health care plans that contract with the OHP.

As part of their OMAP contract, these health plans are required to participate in a statewide prevention project. Medical directors and quality improvement managers from managed care plans collaborate with a variety of state agencies and voluntary organisations to encourage adoption of prevention efforts which might not fit with the business strategies of single plans acting alone. Earlier, the task force had recognised the potential for reaching many of Oregon's smokers through the OHP and had begun collaborating with their staff.

As with most organisations, the OMAP staff, while not in the position of making policy decisions, does assist in the flow of information to agency heads and managed health plan representatives and provides an indispensable role in the decision making process. They also understand the necessary intra-agency lines of communication. Involving the OMAP staff in the health systems task force, especially during the guideline development phase, not only helped them to become more familiar with tobacco intervention in health care, it provided the task force with crucial information about how to develop useful guidelines for Oregon's managed care plans. In this way, OMAP staff became key advocates within the agency as the discussions about the next prevention project began to take shape in the third quarter of 1997. 
Working together with OMAP staff, the health systems task force offered technical assistance to OHP by providing a review of the literature, a rationale for undertaking a population based approach to cessation through health care systems, and the newly developed Oregon designed cessation guidelines. We also provided expert presenters from health systems that had already implemented similar guidelines to describe their experiences and the results. With a significant amount of information and sound rationale for proceeding, the OHP voted in December 1997 to tackle tobacco cessation as their next statewide prevention project.

Framing the tobacco cessation project as a statewide effort was a key turning point in the adoption process for two reasons. First, through statewide collaboration, health plans would share the burden of the costs as members shifted from one plan to another, and also in the benefits, as the effects of cessation initiated in one plan were realised in another plan. The second reason was that by working collaboratively, health plans that were advancing in their efforts to implement these guidelines would influence plans who had not yet started. Additionally, best practices learned from one plan could be shared with others, thereby accelerating the learning for all.

\section{A new challenge: implementation}

The adoption of the Oregon based smoking cessation guidelines by OHP represented an unprecedented step in the collaboration between our statewide tobacco prevention coalition, OHD, the state Medicaid agency, and most of Oregon's managed care plans. We quickly realised that in order to implement these guidelines successfully, we would need to do more than reach agreement; we would need to determine how to implement these guidelines, in all of the participating plans, reaching out to thousands of Oregon providers, and tens of thousands of Oregon tobacco users. While we had a sound, evidence based model for the tobacco cessation guidelines, there were no models for statewide implementation plans.

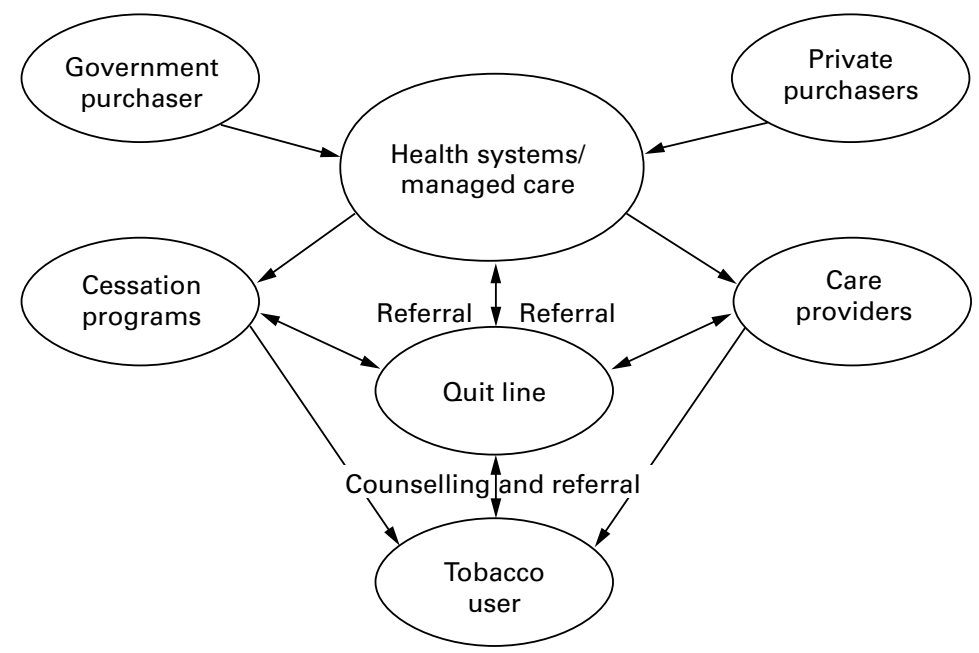

Figure 2 Oregon tobacco cessation project: present.
Buoyed by the enthusiasm and motivation of the health plans to move forward, the now cohesive joint staff of OHD, TOFCO, and OHP began meeting to lay out implementation proposals to be worked out first by the TOFCO health systems task force and then by the OHP task force. The strategy was to set up staggered meetings of the TOFCO health systems task force, which provided the technical input and expertise on the implementation plans, and the OHP task force, which provided practical input needed for the implementation plans to work within managed health care. Our system was to move proposals sequentially through each committee then on to a formal vote for approval so that the implementation process would be supported at all levels. We developed three kinds of plans: an implementation plan, which was specific to the Project Prevention task force and called for adoption of the guidelines by all participating plans, measures for evaluation, training programs, and communication strategies; an evaluation plan that identified specific, common measures for chart audits and progress reports to compare implementation across the different participating health plans; and an information dissemination plan to communicate with plans and plan members through mass mailings and outreach to a variety of audiences. Simultaneous to the development of the implementation proposals, we also prepared and submitted (and were awarded) a special grant to the American Medical Association through the SmokeLess States National Program Office for additional funding to provide training and technical assistance to the health plans outlined in the implementation plan.

Implementation of the statewide tobacco cessation project is well underway. Selected health care leaders in Oregon have received advanced information about the project introduced by a letter from the state governor. Most of Oregon's primary care providers have received the guidelines also with a letter from the governor encouraging their participation. Implementation workshops for health and dental plan representatives have been held and specially developed implementation "tool kits" have been distributed. Outreach to all relevant professional health organisations is underway and telephone and on site technical assistance is available. An additional evaluation project began in the third quarter of 1998 to measure the impact of the project over the next three years.

An important addition to the project has been the initiation of the Oregon quit line in January 1999. In addition to providing initial cessation assistance, the quit line helps link callers with cessation resources available through their health plan or community. The quit line also provides a cessation program with pharmacology for callers who are uninsured. In this way, the quit line serves as an integrated information and referral resource for cessation in Oregon and complements the integration of cessation services in health care systems (fig 2). 
At this time, all participating health plans have identified a cessation coordinator and provide benefits, including pharmacology, to all OHP members. Several of the health plans who do not participate in OHP are also developing benefits programs and services. Important next steps in the implementation of this project are to work with commercial purchasers of health care to include more consistently cessation services in their contracts with health care plans and to develop consumer criteria for programs to help make more informed choices about cessation services.

It is our hope that, together with the statewide tobacco prevention and education program, funded with tobacco tax revenue, the statewide tobacco cessation project will have a significant impact on the rate of tobacco use in Oregon, protecting thousands of additional lives from the needless harm and destruction of tobacco use.

\section{Lessons learned from Oregon}

- It is important to have a group or committee (such as the TOFCO health systems task force) which can provide vision and respected technical expertise to health systems.

- It is important that this group or committee undertake a project that leads to consensus on the cessation strategies that they will promote. This builds the capacity for advocacy (champions). This occurred in Oregon by debating the national AHCPR guidelines until there was strong consensus for and ownership of the Oregon version.

- To work effectively with managed care, you need to begin by building working relationships, helping key individuals to become familiar with both the technical and applied aspects of cessation in managed care. Involving them as part of our statewide coalition committee was especially helpful.

- While presenting the evidence base was crucial to demonstrate the validity of the guidelines, in the end, adoption of the guidelines came because it was "the right thing to do". This argument won out over the arguments about cost.

- No matter which group or individual you are working with, you need to be prepared to discuss both the macro, or systems perspective, as well as the micro, or treatment delivery perspective. The project is only understood when it is described on multi-levels.

- Providing ongoing technical assistance is crucial. Health plans, once on board with the project, will implement a plan that is already developed and will take advantage of any assistance available. They are too busy to do the development and assistance themselves. Persistence is essential. While interest in cessation in managed care is growing, the challenges are substantial. You have to be prepared to persist.

\section{Importance of partnerships: summary}

Addressing tobacco is a community wide concern which extends beyond conventional health groups. The projects presented demonstrate significant community involvement, concerns from parents and schools, and many other organisations. This, of course, is fertile ground for partnerships among diverse organisations. In general, progressive policies and programs to reduce tobacco use are always well received in public opinion polls, which supports the potential for diverse partnerships among organisations.

The benefits of partnerships are not difficult to promote and they substantially increase the reach of program efforts. Partnerships make sense to individuals and organisations, and cessation is an issue that concerns many people. Thus, promoting partnerships to accomplish goals to reduce tobacco use is not difficult and can improve the outcome.

It helps to promote a particular kind of program or product that represents the project. This specificity seems to provide a focal point for getting people involved, such as the clarity of the "Tar Wars" program and all the different steps to implement the program. That specificity or program identification helps enhance participation. It also makes it much easier to find endorsers and sponsors rather than trying to generate support through more vague approaches such as "Are you interested in working on tobacco? Let's talk about ideas".

The needs of the partners will help define the project. You have to be flexible; you cannot control the outcome. However, the outcome usually improves with the synergy of diverse partners.

Finally, leadership is essential. Good coordination, staffing, and leadership is needed to really move the project along.

The author wishes to acknowledge the American Medical Association through the Robert Wood Johnson Foundation SmokeLess States Initiative for supporting this project along with support from the Oregon Health Division, the Oregon Office of Medical Assistance Programs, and the Oregon Health Plan. The author would also like to acknowledge invaluable assistance in preparing this manuscript from Nancy Clarke, Oregon Health Division, Judith Van Osdol, Office of Medical Assistance Programs, and Dr Charles Bentz, Providence Health Systems.

1 Fiore MC, Bailey WC, Cohen SJ, et al. Smoking cessation Clinical Practice Guideline No 18. Rockville, Maryland: US Department of Health and Human Services, Public Health Service Agency for Health Care Policy and Health Service, Agency for Heath Care Policy and 0692.); <http://www.text.nlm.nih.gov/ftrs/tocview>. 